\title{
Patterns of injury in children and adolescents presenting to a South African township health centre
}

\author{
Karen J Zwi, Anthony B Zwi, Eugene Smettanikov, Neil Söderlund, Stuart Logan
}

\begin{abstract}
Objectives-To describe the patterns and causes of childhood injury presenting to a South African township health centre in 1991.

Design-Retrospective review of clinic held case notes.

Setting-Typical South African urban township within Greater Johannesburg.

Subjects-695 subjects aged 0-19 years presenting as a direct result of injury.

Results-Overall rates of presentation for injury were $6297 / 100000 /$ year $(95 \%$ confidence interval 5463 to 7131 ); $35 \%$ of injuries were caused by violence, $14 \%$ by traffic, and $51 \%$ by other unintentional causes (such as falls and sport injuries). Males had higher rates of presentation than females for violent $(p<0.001)$ and unintentional injuries $(p<0.01)$, but rates were similar for traffic injuries. The highest rates were for injuries caused by violence in 15-19 year-old males and were 9319/100 000/year.
\end{abstract}

Conclusions-Rates are lower than in more developed countries. However, they appear to represent the more severe end of the spectrum of injury severity. The rates are similar for those below age 10 years and higher for those above age 10 years compared with severe injury rates in other studies. These data are likely to underestimate true rates. The risk of injuries caused by violence increase with age and these injuries are more serious than those due to other causes. Males are at higher risk for all types of injury except traffic injury.

(Injury Prevention 1995; 1: 26-30)

Keywords: health services research, violence, South Africa, unintentional injuries.

There is little information on injury incidence in less developed countries. Baseline data against which changes in health status and the effectiveness of interventions can be measured is of particular value at this time of transition in South Africa. The objective of this study was to describe the patterns and causes of injury sustained by children and adolescents presenting to a township health centre in South Africa. A community based survey would be both expensive and, in this setting and time, dangerous. Access to death records held at the
Johannesburg District Surgeon's Office was not possible. National mortality rates are not available for black South Africans outside of a number of selected magisterial districts, so no routine national statistics were available for comparison. Collection of morbidity data based on presentation to the only health centre in the township seemed the most feasible way to begin research on injury in this community. The baseline results found in this study will be used to develop further research questions and prevention strategies.

Alexandra Township is an area of 5 square km situated within Greater Johannesburg, South Africa. Initially intended to accommodate 30000 people, the most recent population estimate is nearly 142000 (D Coetzee, personal communication). In 1990 the average household income was R750.00 ( $£ 150.00)$ per month. ${ }^{1}$ The disease profile in children of Alexandra resembles that of a typical less developed population: infectious diseases, malnutrition, and injury are the most common reasons for presenting to the health centre. ${ }^{2}$

Curative health care is provided by Alexandra Health Centre, 21 general practitioners, and several traditional healers. The health centre has adult and paediatric outpatient departments and a 24 hour casualty service operating seven days a week. Casualty staff are accustomed to dealing with trauma and able to deal with moderately serious injuries on site. Facilities for radiography, setting of fractures, extensive suturing, and removal of foreign bodies are available, as well as resuscitation and overnight observation facilities. Tembisa Hospital, the official referral hospital, is $25 \mathrm{~km}$ away. Acceptance of referrals to the closer teaching hospital relies on the goodwill of individual doctors at that hospital and involves official referral and transfer. Referrals are seldom undertaken unnecessarily and typically require admission.

Children and adolescents in Alexandra are at risk of injury for several reasons. There are high levels of interpersonal violence and environmental conditions are hazardous: $37 \cdot 4 \%$ of the population live in makeshift squatter dwellings; only $20.8 \%$ of households have access to electricity. ${ }^{2}$ Roads are poorly maintained; child seat restraints are not mandatory; and drink-driving and speed legislation inadequately enforced. There are few child care facilities and children are often cared for by inexperienced supervisors. Despite these issues, injury in this and similar communities has only been recently raised as a public health concern and is inadequately studied. 


\section{Population and methods}

The study population consisted of subjects aged 0-19 years who presented to Alexandra Health Centre casualty department between 1 January and 31 December 1991 as a direct result of an injury. Only the first presentation for a given injury was included. All those who presented to casualty were included in the analysis of patterns and causes of injury; only residents were included in the calculation of incidence rates.

An injury was defined as a wound, closed injury, or burn of any type and site (ICD-9 codes 800-829; 850-904; 940-959). Poisoning and drowning were excluded as many children with these injuries presented to the paediatric medical rather than the casualty department and their records were not available for this study. Child sexual abuse was also excluded; other forms of child abuse were likely not to be identified as such, although any injuries sustained as a result would have been included in the sample.

Information was obtained retrospectively from clinic held routine records. A simple random sample of eight days per month was selected. The casualty attendance register was used to identify the injury presentations on each selected day, and these records were drawn from the record archives. A standard form was used to record the required information from case notes. Demographic and temporal details were collected. Cause of injury was classified into one of four categories: violence (includes assaults, gunshots), traffic, other unintentional (includes falls, sport injuries, burns), and unknown. Details of the injury (for example fracture or dislocation, surface area, and causative agent in the case of burns), localisation of the injury, and management were recorded. Data abstraction was performed by trained research nurses with experience of data collection from similar studies at the health centre, and was supervised by one of the authors, a physician (ES). The data was coded and entered onto Epi-Info 5 computer program, which was used to perform statistical analysis.

Estimates of injury rates were calculated, directly standardised for the day of the week of presentation, using a method described by Nell and Brown ${ }^{3}$ and described below:

Rates $/ 100000$ population/year $=\frac{\mathrm{C}_{\mathrm{i}} \times 100000 \times 365}{\mathrm{n} \times \mathrm{P}_{\mathrm{i}}}$

$\mathrm{C}_{\mathrm{i}}=$ cases in subgroup day, $\mathrm{n}=$ number of days sampled, and $\mathrm{P}_{\mathrm{i}}=$ population of subgroup. This approach was necessary because of differential proportions on different days of the week in the sample, and significantly higher rates of injury over weekends.

Table 1 Rates of presentation for injury/100 000 population/year by sex and age

\begin{tabular}{llll}
\hline Age group (years) & Males & Females & Total (95\% CI) \\
\hline $0-4$ & 3339 & 2067 & $2725(1972$ to 3478$)$ \\
$5-9$ & 4625 & 2665 & $3584(2632$ to 4537$)$ \\
$10-14$ & 9355 & 6688 & $8033(6460$ to 9610$)$ \\
$15-19$ & 16700 & 8761 & $12425(10290$ to 14560$)$ \\
Total $(95 \%$ CI) & $7924(6842$ to 9006$)$ & $4770(3945$ to 5595$)$ & $6297(5463$ to 7131$)$ \\
\hline
\end{tabular}

Of the injury attendances identified from the casualty attendance register, $15 \%$ of case notes could not be found. This is likely to be due to the fact that files are stored according to date of last attendance, and some cases might have reattended the clinic before data collection began. Data in the casualty register were insufficient to characterise the missing records in terms of type or cause of injury, age, or outcome. All rates were consequently inflated by a factor of $15 \%$. Population estimates used were those from the 1992 demographic survey (D Coetzee, personal communication). Confidence limits around the incidence estimates for age, sex, and injury cause were calculated using the standard deviations of daily injury incidence, which were scaled up using the method above. ${ }^{3}$ Estimates of severity of injuries were performed in two ways. Firstly, severity of injuries was classified according to an accident and emergency severity coding system devised by Steward-Brown (appendix). ${ }^{4}$ Secondly, following Davidson et al, ${ }^{5}$ severe injury rates, defined as the rate of injuries requiring admission to hospital or dying, were calculated for Alexandra residents. For the reasons outlined above, we felt justified in assuming that all those referred to hospital were admitted. As mortality data from injury for the area studied were not available to us, only deaths occurring on the clinic premises were recorded. Consequently this would give rise to an under enumeration of severe injuries in the study population. As expected, insufficient detail on physiologic parameters (for example pulse rate, body weight) was recorded in routine records to allow the use of the physiologic trauma score or the abbreviated injury score.

\section{Results}

On the 96 randomly selected days, 695 subjects aged 0-19 years met the inclusion criteria. Altogether $591(85 \%)$ records were located; $538(91 \%)$ of these were Alexandra township residents. Estimated annual rate of presentation for Alexandra residents aged 0-19 years was $6297 / 100000$ (95\% confidence interval (CI) 5463 to 7131 ) for all injury types. There was a steady rise in injury rates with age, reaching a peak at 19 years (table 1 ). The highest rate, in the 15-19 year age group, was $12425 / 100000$ (95\% CI 10290 to 14560 ).

The cause of injury was recorded in 509 $(86 \%)$ cases. Thirty five per cent of these were violence related, $14 \%$ traffic, and $51 \%$ due to other unintentional causes. Traffic injuries comprised between 10 and $32 \%$ of the total over the whole age range, whereas violent injuries showed a dramatic rise with age (figure). No violent injuries were recorded under the age of 8 years, but this is likely to be a spuriously low figure, reflecting both the reluctance of clinicians to ask about domestic violence towards young children, and the reluctance of parents to admit such violence, or indeed violence by others when they were responsible for looking after the child concerned.

Sex was recorded for $575(97 \%)$ subjects; 355 $(61 \cdot 7 \%)$ were male and $220(38 \cdot 3 \%)$ female. 


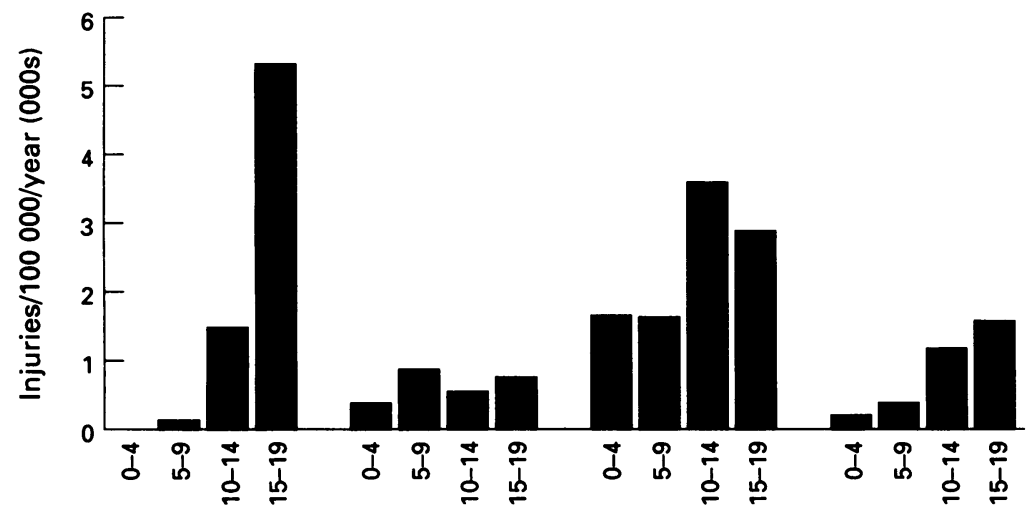

Violence Uraffic Unintentional Unknown

Rates of presentation for injury/100 000/year by cause and age group.

Table 2 Rates of presentation for injury/100 000 population/year by sex and cause

\begin{tabular}{llll}
\hline Injury cause & Males & Females & Total (95\% CI) \\
\hline Violence & 2600 & 1200 & $1880(1472$ to 2288$)$ \\
Traffic & 784 & 709 & $745(510$ to 980$)$ \\
Unintentional & 3458 & 2103 & $2757(2278$ to 3235$)$ \\
Unknown & 1082 & 753 & $916(658$ to 1174$)$ \\
Total $(95 \% \mathrm{CI})$ & $7924(6842$ to 9006$)$ & $4765(3945$ to 5595$)$ & $6298(5463$ to 7131$)$ \\
\hline
\end{tabular}

Table 3 Rates of presentation for injury/100 000 population/year by sex, age group, and cause

\begin{tabular}{|c|c|c|c|}
\hline Injury cause & Males & Females & $\begin{array}{l}\text { Male:female } \\
\text { rate ratio }\end{array}$ \\
\hline $\begin{array}{l}0-4 \text { years } \\
\text { Violence } \\
\text { Traffic } \\
\text { Unintentional } \\
\text { Unknown }\end{array}$ & $\begin{array}{l}\star \\
292 \\
2599 \\
448\end{array}$ & $\begin{array}{l}\star \\
656 \\
1336 \\
75\end{array}$ & $\begin{array}{l}\star \\
0 \cdot 44 \\
1.95 \\
5.97\end{array}$ \\
\hline $\begin{array}{l}\text { 5-9 years } \\
\text { Violence } \\
\text { Traffic } \\
\text { Unintentional } \\
\text { Unknown }\end{array}$ & $\begin{array}{l}326 \\
1379 \\
2375 \\
544\end{array}$ & $\begin{array}{l}75 \\
751 \\
1528 \\
385\end{array}$ & $\begin{array}{l}4 \cdot 34 \\
1 \cdot 84 \\
1 \cdot 55 \\
1 \cdot 41\end{array}$ \\
\hline $\begin{array}{l}\text { 10-14 years } \\
\text { Violence } \\
\text { Traffic } \\
\text { Unintentional } \\
\text { Unknown }\end{array}$ & $\begin{array}{l}2025 \\
698 \\
5442 \\
1192\end{array}$ & $\begin{array}{l}1467 \\
597 \\
3035 \\
1589\end{array}$ & $\begin{array}{l}1 \cdot 38 \\
1 \cdot 17 \\
1 \cdot 79 \\
0 \cdot 75\end{array}$ \\
\hline $\begin{array}{l}\text { 15-19 years } \\
\text { Violence } \\
\text { Traffic } \\
\text { Unintentional } \\
\text { Unknown }\end{array}$ & $\begin{array}{l}9319 \\
974 \\
3966 \\
2441\end{array}$ & $\begin{array}{l}3692 \\
831 \\
2914 \\
1325\end{array}$ & $\begin{array}{l}2 \cdot 52 \\
1 \cdot 17 \\
1 \cdot 36 \\
1 \cdot 84\end{array}$ \\
\hline
\end{tabular}

$\star$ Rate could not be estimated because no events occurred.

Table 4 Rates of violent injury by age, sex, and method of injury/100 000/year

\begin{tabular}{|c|c|c|c|c|}
\hline & Combined rate & Males & Females & $\begin{array}{l}\text { Male:female } \\
\text { rate ratio }\end{array}$ \\
\hline \multicolumn{5}{|l|}{$5-9$ years } \\
\hline Bite & * & $\star$ & * & $\star$ \\
\hline Blunt injury & $\star$ & $\star$ & $\star$ & $\star$ \\
\hline Stab wound & 120 & 170 & 75 & $2 \cdot 3$ \\
\hline Gunshot & 40 & 85 & $\star$ & $\star$ \\
\hline \multicolumn{5}{|l|}{$10-14$ years } \\
\hline Bite & $\star$ & * & $\star \star$ & $\star$ \\
\hline Blunt injury & 849 & 838 & 860 & $1 \cdot 0$ \\
\hline Stab wound & 849 & 1210 & 478 & 2.5 \\
\hline Gunshot & 141 & 186 & 96 & $1 \cdot 9$ \\
\hline \multicolumn{5}{|l|}{$15-19$ years } \\
\hline Bite & 120 & 173 & 74 & $2 \cdot 3$ \\
\hline Blunt injury & 1995 & 2340 & 1701 & $1 \cdot 4$ \\
\hline Stab wound & 3352 & 5374 & 1627 & $3 \cdot 3$ \\
\hline Gunshot & 639 & 1214 & 148 & $8 \cdot 2$ \\
\hline \multicolumn{5}{|l|}{ All ages } \\
\hline Bite & 28 & 39 & 18 & $2 \cdot 1$ \\
\hline Blunt injury & 644 & 704 & 588 & $1 \cdot 2$ \\
\hline Stab wound & 994 & 1505 & 515 & 2.9 \\
\hline Gunshot & 189 & 332 & 55 & $6 \cdot 0$ \\
\hline Total & 1855 & 2580 & 1176 & $2 \cdot 2$ \\
\hline
\end{tabular}

^Rate could not be estimated because no events occurred.
Overall, males had higher rates of presentation than females for violent $\left(\chi^{2} 23.5 ; \mathrm{p}<0.01\right)$ and unintentional injuries $\left(\chi^{2} 17 \cdot 7 ; \mathrm{p}<0.01\right)$, in contrast to traffic injuries where rates were similar (table 2). Unintentional injuries accounted for the highest injury rates in both males and females in all age categories until age 15 years. Violence was responsible for higher rates of injuries than traffic by age 10-14 years, and than unintentional injuries by age 15-19 years (table 3 ). The overall male:female rate ratio was 1.7 for all injuries, but varied with age and cause of injury. For known causes, the most marked gender difference was in the 15-19 year category for violent injuries, where the male:female rate ratio was $2 \cdot 52$.

Presentation by cause differed depending on day of the week with $60 \%$ of all violent injuries and $56 \%$ of all traffic injuries presenting on Friday, Saturday or Sunday, whereas $38 \%$ of unintentional injuries presented on these days. Although no data were collected, there is strong anecdotal evidence that much of the excess of violent and traffic related injuries is related to increased alcohol consumption over weekends. Furthermore, migrant workers returning home for the weekend are likely to increase the volume of traffic on township roads on Friday and Sunday evenings.

Half of all the unintentional injuries below 3 years were attributable to burns. Forty four children sustained burns or scalds, 19 of whom were below the age of 3 years. The most extensive burn involved a surface area of $20-30 \%$ in a 7 year old child. There were four children in whom surface area involvment was $10-20 \%$; the remaining burns were less than $5 \%$ in surface area. Half of the burns were caused by hot water and the remainder by fire and hot objects.

Table 4 presents rates of violent injury by age group, sex, and method of injury for ages 5 to 19 years. Blunt injuries and stabbings were the most common, and particularly high male: female ratios were evident for gun and knife wounds.

Violence was responsible for $60 \%$ of the head injuries and $67 \%$ of the trunk injuries. Violence, as compared with other causes, was associated with head, face, or neck injury $\left(\chi^{2}\right.$ $47.5 ; p<0.01)$. Eighty one per cent of unintentional injuries involved the limbs, whereas the limbs were involved in $37 \%$ of violent injuries.

There were $153(26 \%)$ children and adolescents who sustained injuries at multiple sites; $52(10 \%)$ subjects presented with fractures. The estimated fracture rate was 399/100 000 year for 0-9 year olds and 1053/100 000 year for 10-19 year olds. A further 10 presented with abdominal or thoracic organ damage, 14 with eye, and 13 with nerve injuries. Two children arrived at the health centre alive and died before transfer.

One hundred and seven $(18 \%)$ cases were referred to hospital; the majority $(72.1 \%)$ were fully treated at the health centre and fewer than $10 \%$ of cases received no treatment. One hundred and fifty five $(26 \%)$ required sutures and 17 intravenous infusion. Injuries caused by violence resulted in referral in $28 \%$ of cases, 
whereas injuries due to other causes resulted in referral in $14 \%\left(\chi^{2} 14.2 ; p<0.01\right)$.

Seventeen per cent of injuries were trivial and almost $23 \%$ were moderate or severe using the Stewart-Brown severity coding system. Injuries caused by violence were moderate or severe in $28 \%$ of cases; those from other causes were moderate or severe in $20 \%$ of cases. Severe injury rates calculated on the basis of referral to hospital and deaths at the health centre were $579 / 100000 /$ year for 0-9 year olds, 880 for $10-14$ year olds, and 2879 for 15-19 year olds.

\section{Discussion}

To calculate incidence rates, reliable population denominators are required. The 1992 demographic survey is the most systematically ascertained population data available to date. Rates of annual presentation for non-fatal injuries in this study are lower than rates reported from more developed countries. ${ }^{6-8}$ For instance, a study of children presenting with injuries to hospitals in South Glamorgan reported annual attendance rates of $20000 /$ 100000 in children below 15 years, a rate four times as high as the corresponding age group in this study. ${ }^{6}$ However, rates of presentation do not simply represent rates of injury incidence. Use of data from only one of a number of health care providers would be expected to underenumerate rates. In South Africa traditional healers and general practitioners may see and treat a significant proportion of cases, especially the more minor injuries. Although the closest hospitals are some distance away, some cases may present directly to hospital casualty departments. Of the 3477 injuries presenting on the sample days, a total of 512 did not have an age recorded. If children and adolescents were proportionately represented among these records, rates would have been approximately $17 \%$ higher than we estimated. Data on injuries due to drowning, poisoning, and sexual abuse were not collected by this study. Approximate rates of sexual abuse can be estimated from a previous study (1988-90) at the Alexandra health centre, however.' Applying 1992 population figures, reported rates of sexual abuse in the 0-9 year age group were approximately $340 / 100000 /$ year for girls and $14 / 100000$ for boys.

Patients would incur some degree of copayment or charge at any provider, as well as having to wait relatively long periods for treatment, thus deterring care seeking for minor injuries, and skewing the severity picture towards the more severe end of the spectrum. In a recent study of accident and emergency attendances of 0-14 year olds in south east London, in which the same classification of injury severity was used, only $12 \%$ of injuries were classified as moderate or severe compared with $20.6 \%$ in $0-14$ year olds in this study (G Laing, personal communication). In the London study $33 \%$ of injuries were classified as trivial compared with $17 \%$ in Alexandra. In this study $18 \%$ below age 15 years were assessed by the casualty doctor as requiring admission and referred to hospital. In comparison with this, only $4.5 \%$ of children below 15 years presenting to accident and emergency departments in the UK are admitted or referred to a specialist or other hospital. ${ }^{610}$

Other authors have included death rates in estimates of the incidence of severe injury. ${ }^{511} \mathrm{~A}$ study of deaths due to non-natural causes in greater Cape Town, South Africa reported that $65 \%$ of all bodies of children under 15 years were taken directly to the police mortuary from the scene of the injury. ${ }^{12}$ Rates of hospital admission are not available for this study, but the barriers to referral make it likely that virtually all those referred will be admitted. Comparison with severe injury reported from a study in New York City (based on admissions plus deaths in hospital) suggests similar rates for those aged below 10 years, slightly higher rates for 10-14 year olds in Alexandra (880/ 100 000/year compared with 732/100 000/year) and 2.4 times higher rates for 15-19 year olds in Alexandra (2879/100 000/year compared with $1214 / 100000 /$ year). ${ }^{5}$

A striking feature of this study is the extent of violence related injuries, particularly in 15-19 year old males. The annual risk of presentation in this group is $9 \%$. Younger children are also at considerable risk of injury caused by violence even though violence is not the leading cause of injury. One in every 49 male and one in every 68 female children in the 10-14 year age group is likely to present to the health centre with injuries caused by violence each year. Injuries resulting from violence were more likely to be classified as moderate or severe, and were more likely to result in referral to hospital than those from other causes. Violence related injuries were also more likely to involve the head, face, or neck injuries compared with traffic and unintentional injuries.

Males are at higher risk of most categories of injury. The exception is traffic, where the overall ratio of males to females is $1 \cdot 1$. This contrasts with studies from Canada and the US, where males are consistently at higher risk. ${ }^{1314}$ The most striking gender differences is in the 15-19 year old group for violent injuries, where the risk in males is more than double that in females. The gender difference for violent injuries in this age group is less marked than has been found in other studies due to the high absolute rates of violent injuries in Alexandra females. ${ }^{15}$

The relatively large number of burns seen in this study, many of which were severe, illustrates the hazardous nature of the environment. The children at higher risk of burns are those aged below 3 years. The fact that all burns were caused by fire (either house fires or cooking/ heating fires), hot water and hot objects, and that there were no chemical or electrical burns reflects the cooking and heating practices in the township.

\section{Conclusions}

The authors would hope that this study goes some way to highlighting the extent of ill health due to injury in developing country popula- 
tions. In the South African context, high rates of violent injury appear to be a particularly striking feature.

Considerable difficulties may be encountered in conducting this type of study in a developing country setting, however. The use of routine data is a low cost and easily available method of estimating the rate of injury in a community. It cannot, however, determine risk factors implicated in different types of injury, nor estimate the likelihood of disability or death after injury. Interpretation of the findings of this study depends on comparing rates with those found in other studies. There are few data available that can be used for this purpose: many studies document mortality rates; others report morbidity rates ranging from household surveys to hospital admissions. Although an attempt was made at estimating injury severity, the lack of data from other studies using the same scoring system and expressing the results as rates makes comparisons very difficult. Furthermore, comparisons of rates of presentation is in itself complex. The likelihood of presentation is determined by factors such as thresholds for seeking health care, cost, and accessibility of services as well as the incidence of injury. A standardised approach to collection and presentation of injury data would make the growing body of descriptive epidemiological research considerably more useful in setting priorities for further, more detailed, research and policy recommendations.

The public health implications of our research are:

- Injury is an important public health problem in children and adolescents in a typical South African township and likely to be important in other similar settings.

- Analysis of routine data is useful in developing further research questions and intervention strategies.

- The interpretation of injury rates is difficult without a universally standardised and simple classification system and without information about presentation rates to other health care providers.

Our thanks to Ros Hirschowitz, Antonio Fernandes, Matsia Ratsaka, Thuli Shongwe, Laetitia Vena of Alexandra Health Centre and to Leslie Davidson for comments on an earlier draft. This study was conducted with support from the Overseas Development Administration (UK), under the auspices of the Development Administration (UK), under the auspices of the Policy Unit, London School of Hygiene and Tropical Medicine.

1 Alexandra Health Centre and University Clinic 63rd annual report. 1992.

2 Ferrinho Pde LGM, Robb D, Mhlongo A, et al. A profile of Alexandra. S Afr Med ๆ 1991; 80: 374-7.

3 Nell V, Brown DSO. Epidemiology of traumatic brain injury in Johannesburg-2. Morbidity, mortality and etiology. Soc Sci Med 1991; 33: 289-96.

4 Reynolds G. Health needs assessment: accident and emergency services. Worcester and District Health Authority Health report. Worcester: Department of Public Health Medicine, 1991: 24-31.
5 Davidson LL, Durkin MS, O'Connor P, Barlow B, Heagarty MC. The epidemiology of severe injuries to children in northern Manhattan: methods and incidence rates. Paediatr Perinat Epidemiol 1992; 6: 153-65.

6 Sibert JR, Maddocks GB, Brown BM. Childhood accidents - an endemic of epidemic proportions. Arch Dis Child 1981; 56: 225-65.

7 Agass M, Mant D, Fuller A, Coulter A, Jones L. Childhood accidents: a practice survey using general practitioner's records and parental reports. Br $\mathcal{F}$ Gen Pract 1990; 40: records

8 Davidson LL, Hughes SJ, O'Connor PA. Preschool behaviour problems and subsequent risk of injury. Pediatbehaviour problems and

9 Howard PA, Marumo LP, Coetzee DJ. Child abuse in Alexandra - a clinic-based study and community programme. S Afr Med f 1991; 80: 393-6.

10 Consumer Safety Unit/Department of Trade and Industry. - Home and leisure accident research. 1990 data. Fourteenth annual report of the home accident surveillance system. London: DTI, 1992

11 Davidson LL, Durkin MS, Kuhn L, O`Connor P, Barlow B, Heagerty MC. The impact of the safe kids/healthy neighborhoods injury prevention program in Harlem, 1988 through 1991. Am $\mathcal{F}$ Public Health 1994; 84: 1-7.

12 Knobel GJ, De Villiers JC, Parry CDH, Botha JL. The causes of non-natural deaths in children over a 15-year period in greater Cape Town. $S$ Afr Med $f$ 1984; 66: period in

13 Dougherty G, Pless IB, Wilkins R. Social class and the occurrence of traffic injuries and deaths in urban children. occurrence of traffic injuries and deaths

14 Rivara FP. Epidemiology of violent deaths in children and adolescents in the United States. Pediatrician 1985; 12: $3-10$

15 Davidson LL. Violence to children and youths in urban communities. Children and violence. Washington: Ross Laboratories and Ambulatory Pediatric Association, 1992: 21-9.

16 Butchart A, Nell V, Yach D, et al. Epidemiology of non-fatal injuries due to external causes in Johannesburg-Soweto. Part II. Incidence and determinants. $S$ Afr Med $\mathcal{F} 1991$; 79: 472-9.

\section{Appendix}

INJURY SEVERITY CLASSIFICATION SYSTEM

(SARAH STEWART-BROWN)

Injury severe:

Major trauma

Crush injury: not digits

Foreign body: inhaled

Burns/scalds: $\geqslant 10 \%$ surface area

Fracture: neck/spine/rib/pelvis

Head injury: unconscious $\geqslant 5$ minutes

Poisoning: admitted to intensive treatment unit

Near drowning

Other

Injury moderate:

Finger/toe crush injury/traumatic amputation

Burns/scalds: $\geqslant 1 \%$ and $<10 \%$ surface area or full thickness or burns of eye/genitals

Dislocation

Fracture long bone: upper limb/lower limb

Spine injury: admitted

Head injury: admitted or unconscious $<5$ minutes

Nerve injury

Poisoning/ingestion: admitted or stomach washout

Other trauma: admitted

Other

\section{Injury minor:}

Laceration: with sutures

Sprain/strain: support bandage

Foreign body: eye/ear/swallowed

Foreign body: nose

Burns/scalds: $<1 \%$ surface area and not full thickness or eye/genitals

Fracture small bone: hand/foot

Head injury: no concussion

Poisoning/ingestion: not admitted and no stomach Other

Injury trivial:

Superficial open wound

Bruising: no treatment

No injury evident

Laceration: no sutures

Puncture wound: nails, needles, and thorns Other 